\title{
Planktivorous predation on copepods. Evaluation of mandible remains in predator guts as a quantitative estimate of predation
}

\author{
Karin Karlson, Ulf Båmstedt*
}

Department of Fisheries and Marine Biology, University of Bergen, N-5020 Bergen, Norway

\begin{abstract}
Size and shape of mandibles from 8 common species of copepods in Norwegian coastal waters are described, with the aim of using gut contents of copepod mandibles as a precise technique of quantifying predation rates on copepods. The carapace length of 7 of the 8 copepod species could be closely predicted from a general linear regression equation of carapace length versus mandible width. The exception, Temora longicornis, had lower carapace length than expected from the equation. Similarly, the 6 copepodite stages of Calanus finmarchicus produced a highly significant species-specific linear regression equation between carapace length and mandible width, although adult males diverged somewhat by showing a lower carapace length than predicted. A correspondence analysis showed that it was impossible to separate all species and developmental stages from each other based on linear measurements of mandible structures alone, and the skill of a well-trained person is therefore needed. The relationship between individual dry weight and mandible width was well described by a regression equation, which hence could be used to calculate the biomass of consumed copepods, based on the contents of copepod mandibles in the predator's stomach. A comprehensive evaluation of the precision and accuracy in the estimates of prey mass is given, including effects of inter- and intraspecific variability and seasonal variation. By using a power function to regress body mass (mg dry weight) from mandible width $(\mu \mathrm{m})$, the true prey biomass in the stomach content is estimated with a precision of $\pm 20 \%$ or better, when based on more than a few mandibles. However, a considerable seasonal variation in the length/weight relationships of the prey copepods may cause considerable bias in the estimates if not compensated for
\end{abstract}

KEY WORDS: Planktivorous predation - Copepod mandibles - Gut contents - Predation measurements Copepod prey Predation-rate method

\section{INTRODUCTION}

The technique of analysing the stomach contents of a predator in order to define prey composition is widely used for marine animals, especially fish, seabirds and mammals. However, there are identification problems in cases where the predator tears the prey apart and when the identification is dependent upon the structure of soft tissues, which will gradually disintegrate in the stomach during the digestion process. Therefore prey identification will be most accurate if using an anatomical structure from the prey that is speciesspecific, highly inert to the digestion environment, and

- Addressee for correspondence small enough not to be broken apart during ingestion. For fish prey the otholith represents such a component, which consequently has been widely used for predators on fish. Copepods usually make up the main prey for invertebrate predators, and the prey is often torn apart during ingestion, making prey identification based on the size and shape of the whole body impossible. However, the copepod mandibles, which are composed of silica and chitin (Sullivan et al. 1975), are highly resistant. From stomach-content analyses of invertebrate predators it is known that the main part of copepod mandibles will withstand both the mechani$\mathrm{cal}$ and chemical processes during feeding. Enumeration of such mandibles in predator stomach contents has therefore been used to quantify predation, especially for predation by krill (Stuart \& Pillar 1990. 
Barange et al. 1991. Gibbons et al. 1991a, b), and chaetognaths (Øresland 1987, 1990, Falkenhaug 1991, Stuart \& Verheye 1991, Gibbons 1992). Because the mandibles usially have a species-specific shape and size (Beklemishev 1959, Itoh 1970, Sullivan et al. 1975) it is also possible to identify the species. In this study we describe the mandibles of 8 common copepod species in Norwegian coastal waters, based on shape and size measurements. We also evaluate the method of estimating prey biomass from mandible occurence in predator guts. Results from the method in practical use on krill species and an evaluation of some critical factors will be presented in a separate paper (Karlson \& Båmstedt unpubl.).

\section{MATERIAL AND METHODS}

The copepods were collected in Raunefjorden $\left(60^{\circ}\right.$ $16^{\prime} \mathrm{N}, 5^{\circ} 11^{\prime}$ E) south of Bergen, Norway. A conical net, $1 \mathrm{~m}$ diameter, $200 \mathrm{\mu m}$ mesh size, equipped with a nonfiltering cod end, was hauled vertically from $100 \mathrm{~m}$ to the surface. Samples were taken on 15 occasions in May, August, September and October 1992. The animals were kept alive in a $50 \mathrm{l}$ tank and transported back to the laboratory within $2 \mathrm{~h}$ of collection. Copepods were sorted live under a stereo microscope (Wild M5) and only adult females from 8 of the most common species were used, except for Calanus finmarchicus, for which adult males and the 5 juvenile copepodite stages were also included. The carapace length was measured on fresh material, with 25 or $50 \times$ magnification, with a precision of 16 and $8 \mu \mathrm{m}$, respectively. The mandibles were then dissected free. Before microscopic slides were prepared, the mandibles were kept in glycerine/water (1/1) for 20 min and then dyed with methylene blue. Drawings of the mandibles were made by using a drawing tube connected to a Leitz, Dialux mod. 20, microscope. Mandible size was analysed using the Zeus Image Analysis System (ZIA, A/S Pixelwerks, Bergen; Estep \& MacIntyre 1989). Four different morphometric measurements were made (Fig. 1). $\mathrm{L}_{1}$ defines the total width of the toothed edge, whereas $L_{2}$ is the measured width at the base of the toothed edge. $\mathrm{L}_{3}$ represent the height and $\mathrm{L}_{4}$ the width of the ventral-most tooth, not including the tooth crown. Measurements were only made on the toothed edge of the mandible since mandibles in a predator's stomach are usually broken (pers. obs.). The siliceous tooth crowns (Beklemisjev 1954) were not included in the measurements because they are worn down to varying degrees (Beklemisjev 1959). All the morphometric data were used in a correspondence analysis (Braak 1986) in order to give a comprehensive overview. Tests on significant differences in the mor-
Fig. 1 Definition of the 4 length measurements $\left(\mathrm{L}_{1}\right.$ through $\left.\mathrm{L}_{4}\right)$ performed on the copepod mandibles phometric measurements were made by comparing the $95 \%$ confidence intervals of the means and defining significant difference as non-overlapping confidence intervals. In order to determine the relationship between individual dry weight and carapace length of C. finmarchicus, a group of 40 to 60 individuals of a given developmental stage was measured for individual carapace length, dried on a microscope slide for $2 \mathrm{~h}$ at $60^{\circ} \mathrm{C}$ and then weighed. Thus, individual variability in body size is given by the variance in carapace length, whereas individual dry weight is only given as a single value. The general relationship between individual dry weight and mandible width was calculated on the basis of all developmental stages of $C$. finmarchicus collected in August and 6 additional copepod species, ranging in dry weight from 28 to $278 \mu \mathrm{g}$. These were collected at the end of September and beginning of October, and between 9 (Euchaeta norvegica) and 71 (Acartia sp.) individuals were used in the single dry-weight measurement made on each species. A geometric mean functional regression (Ricker 1973) was used in addition to the standard regression in the size relationships calculated, but excluded in the presentations, as differences were minor.

\section{RESULTS}

\section{Adult females from 8 species of copepods}

The shape and size of the mandibles showed specific features in all species (Fig. 2, Calanus finmarchicus in Fig. 3). Metridia longa and Metridia lucens had very similar mandibular shapes but differed in size, as would be expected from their different body sizes. The mandibular width $\left(L_{1}\right)$ of $M$. longa was on average $32 \%$ greater than that of $M$. lucens, parallel to a 

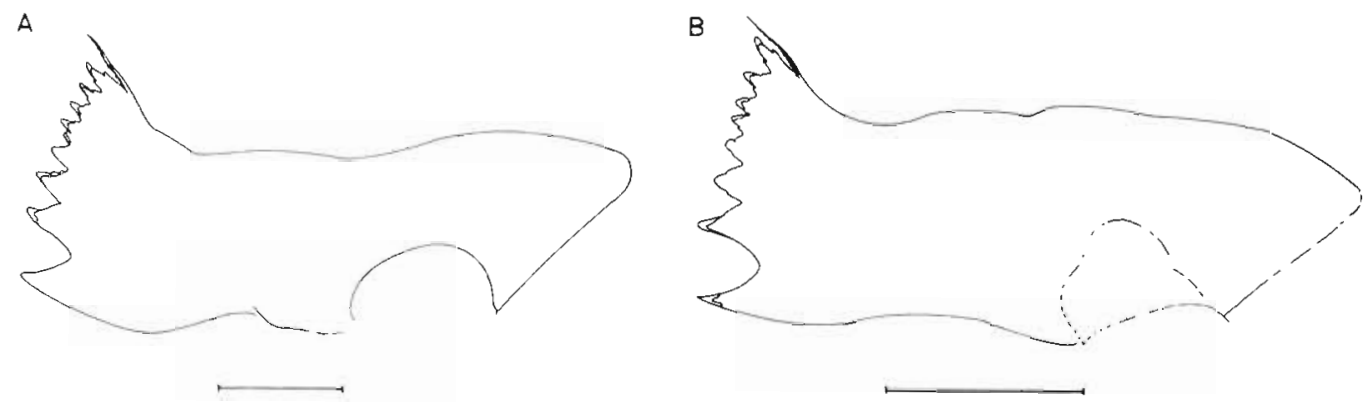

Fig. 2. Schematic drawings of the mandibles of 7 copepod species (adult females only), dissected from fresh specimens. Details shown only for the toothed edge. Scale bars $=100 \mu \mathrm{m} . \mathrm{A}=$ Metridia longa, $\mathrm{B}=$ Metridia lucens, $\mathrm{C}=$ Centropages typicus, $\mathrm{D}=$ Temora longicornis, $\mathrm{E}=$ Pseudocalanus minutus, $\mathrm{F}=$ Acartia sp., $\mathrm{G}=$ Oithona sp.
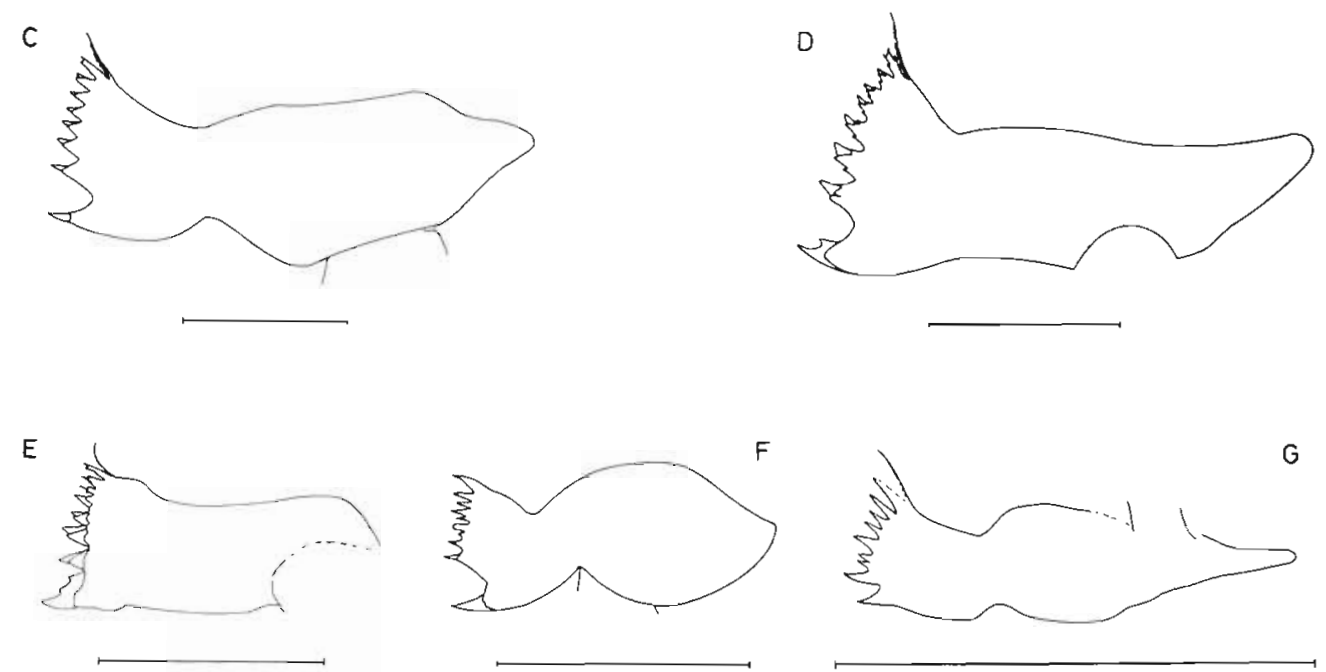

$54 \%$ greater carapace length. The mandibular shape of Temora longicornis and Centropages typicus was somewhat similar to the 2 Metridia species, but the toothed edge (Fig. 2) and average size of the mandibles (Table 1) differed clearly. Oithona sp. was characteristic by its mandibular shape and small mandibular width (Fig. 2, Table 1). The 8 species were significantly different in their average mandibular width, in spite of similar carapace lengths for $T$. longicornis, Pseudocalanus minutus and Acartia sp. (Table 1). The correspondence analysis gave a full separation of Pseudocalanus minutus and Oithona sp. from the other species, partial separation by $T$. longicornis and Acartia sp., and complete mixing of the other 4 species. We therefore conclude that a correct species identification cannot be made from the 4 length measurements alone, but must be based also on the specific shapes (Figs. $2 \& 3$ ).

The average values for the 4 mandibular size measurements $\left(L_{1}\right.$ through $\left.L_{4}\right)$ of the 8 copepod species were used as independent variables in estimating copepod carapace length from mandible size. All 4 variables were closely correlated with carapace length and a linear regression equation gave a coefficient of determination varying between 0.843 and 0.853 . By excluding Temora longicornis the regression was improved considerably, giving a coefficient of determination between 0.964 and 0.966 . The mandibular width $\left(L_{1}\right)$ was selected as the independent variable for further analysis, because it gave the best regression fit $\left(\mathrm{r}^{2}=0.966\right)$, was well defined in all species, and showed a relatively low variance within a species and significantly different average value for all the 8 species (Table 1). The linear equation describing this relationship, based on the mean values for the 7 species (excluding $T$. longicornis) was (Fig. 4):

$$
Y=0.0431+0.0112 X \quad r^{2}=0.966
$$

where $Y=$ carapace length $(\mathrm{mm}) ; X=$ mandible width $(\mu \mathrm{m})$.

The ratios between $L_{1}, L_{2}, L_{3}$ and $L_{4}$ showed some species-specific characters. Pseudocalanus minutus could be clearly defined by its exceptionally high $\mathrm{L}_{1} / \mathrm{L}_{3}$ and $\mathrm{L}_{2} / \mathrm{L}_{3}$ ratios, as well as its low $\mathrm{L}_{3} / \mathrm{L}_{4}$ ratio. In contrast, Oithona sp. was defined by its low $\mathrm{L}_{1} / \mathrm{L}_{3}$ and $\mathrm{L}_{2} / \mathrm{L}_{3}$ ratios, and high $\mathrm{L}_{3} / \mathrm{L}_{4}$ ratio. Acartia sp. was similar to Temora longicornis, but differed by showing somewhat lower $\mathrm{L}_{1} / \mathrm{L}_{4}, \mathrm{~L}_{2} / \mathrm{L}_{4}$ and $\mathrm{L}_{3} / \mathrm{L}_{4}$ ratios. Metridia longa, 

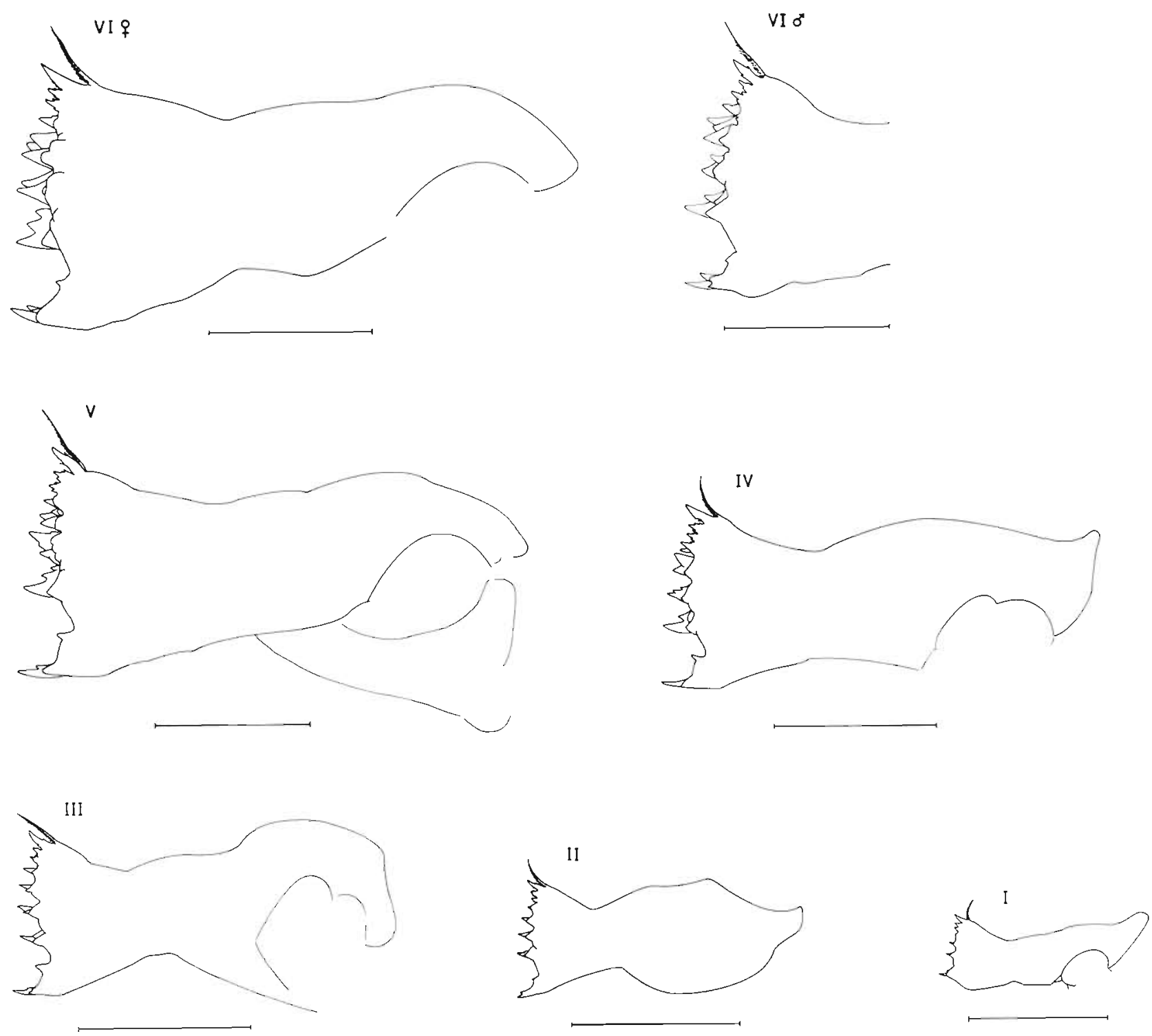

Fig. 3. Calanus finmarchicus. Schematic drawings of the mandibles of copepodite stages I to VI, with the adult sexes shown separately. Details shown only for the toothed edge. Scale bars $=100 \mu \mathrm{m}$

M. lucens, Calanus finmarchicus and Centropages typicus could not be easily identified from any of the ratios given, but the absolute sizes of $\mathrm{L}_{1}$ through $\mathrm{L}_{4}$ (Table 1) as well as the general visual appearance (Fig. 2) gave enough criteria for a proper identification.

\section{Copepodite stages of Calanus finmarchicus}

From copepodite stage II through adulthood the shape of the mandibles of Calanus finmarchicus was relatively uniform, although the toothed edge became more complex with age (Fig. 3). In copepodite stage I a significantly smaller number of teeth had developed and the ventral-most tooth was less pronounced. All size parameters, $L_{1}$ through $L_{4}$, showed significantly different mean values for copepodite stage I through IV and adult females, whereas adult males and stage $\mathrm{V}$ copepodites were not fully separated by these length measurements (Table 1). In a correspondence analysis, using the variables $\mathrm{L}_{1}$ through $\mathrm{L}_{4}$, especially the younger copepodite stages occurred as separate clusters, whereas stage IV copepodites and older stages increasingly overlapped. 


\begin{tabular}{|c|c|}
\hline$E$ & 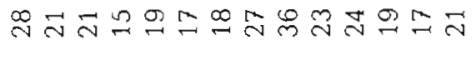 \\
\hline $\begin{array}{l}0 \\
2 \\
\infty \\
\infty\end{array}$ & 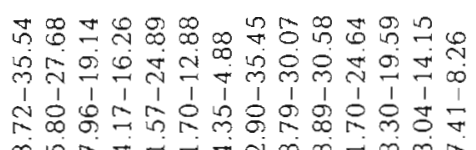 \\
\hline ⿶) & 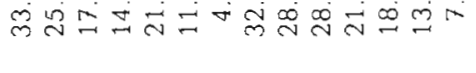 \\
\hline$\underset{\mathbb{E}}{\stackrel{\mathbb{I}}{\mathbb{I}}}$ & 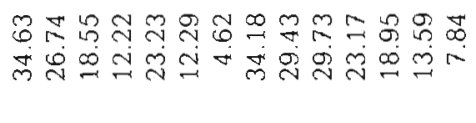 \\
\hline 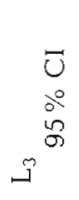 & 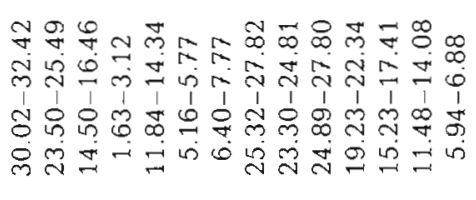 \\
\hline 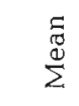 & 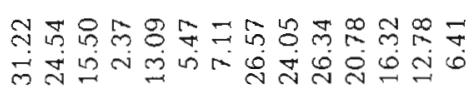 \\
\hline 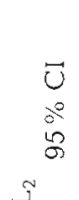 & 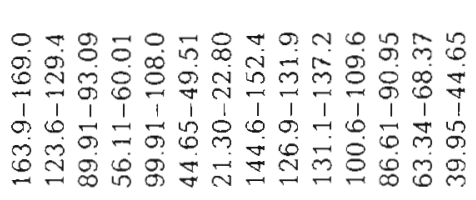 \\
\hline 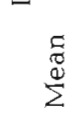 & 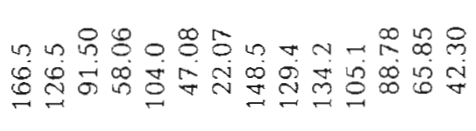 \\
\hline $\begin{array}{l}0 \\
\vdots \\
0 \\
0 \\
\tilde{n}\end{array}$ & 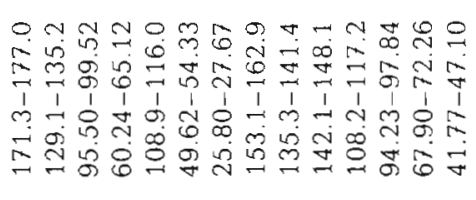 \\
\hline 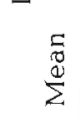 & 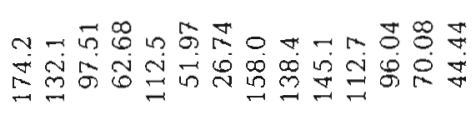 \\
\hline $\bar{\xi}^{\complement}$ & 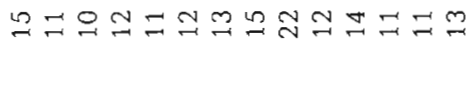 \\
\hline 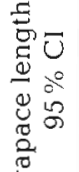 & 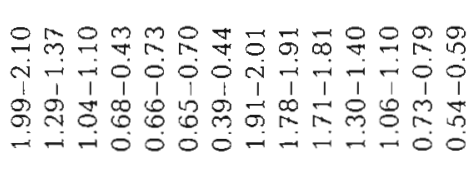 \\
\hline 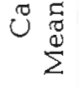 & 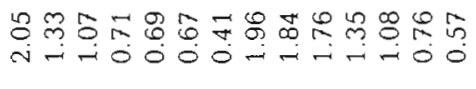 \\
\hline 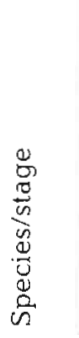 & 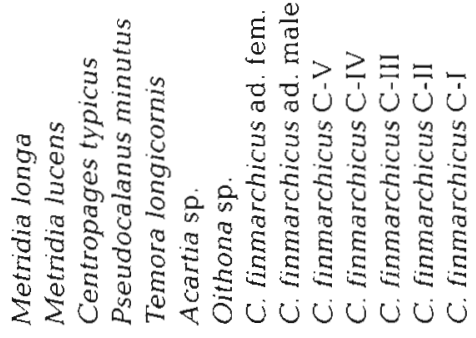 \\
\hline
\end{tabular}

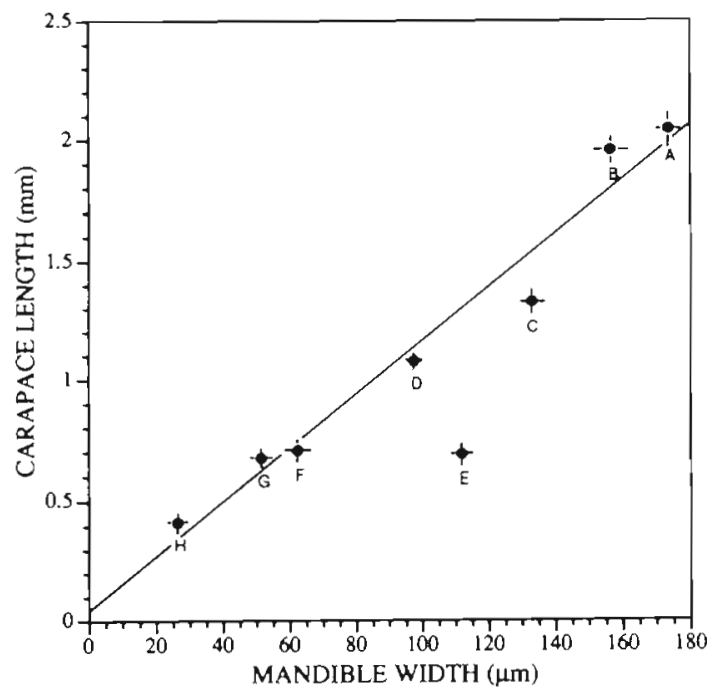

Fig. 4. Relationship between average carapace length (mm) and average mandible width $(\mu \mathrm{m})$ of 8 copepod species (adult females only), sampled at the end of August. Vertical and horizontal bars denote $95 \%$ confidence interval of the carapace length and the mandible width, respectively. $\mathrm{A}=$ Metridia longa, $\mathrm{B}=$ Calanus finmarchicus, $\mathrm{C}=$ Metridia lucens, $\mathrm{D}=$ Centropages typicus, $\mathrm{E}=$ Temora longicornis (not included in regression), $\mathrm{F}=$ Pseudocalanus minutus, $\mathrm{G}=$ Acartia sp., $\mathrm{H}=$ Oithona sp

The relationship between stage-specific mandible width $(X$, in $\mu \mathrm{m})$ and carapace length $(Y$, in $\mathrm{mm})$ for Calanus finmarchicus (Fig. 5) was well described by the linear regression equation:

$$
Y=-0.0690+0.0126 X \quad r^{2}=0.991
$$

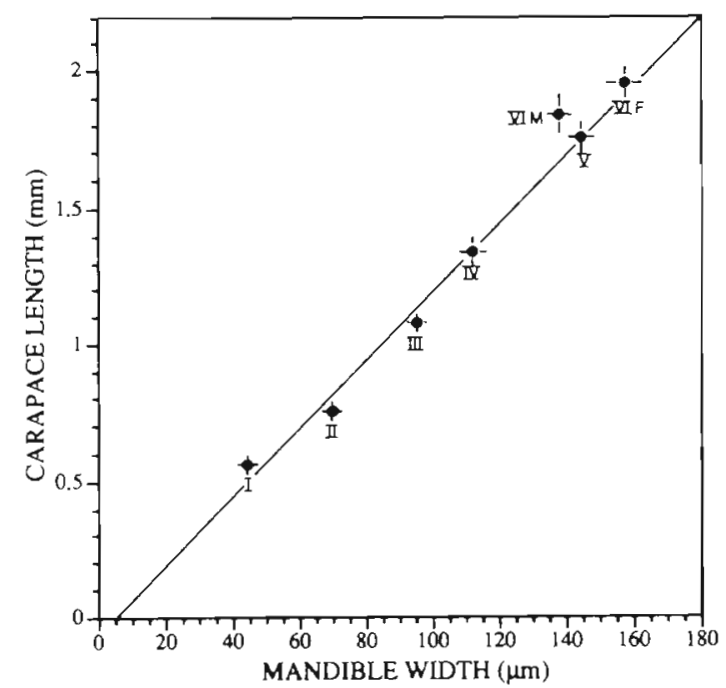

Fig. 5. Calanus finmarchicus. Relationship between average carapace length $(\mathrm{mm})$ and average mandible width $(\mu \mathrm{m})$ of copepodite stages I to VI (excluding adult males). Vertical and horizontal bars denote $95 \%$ confidence interval of the carapace length and the mandible width, respectively 
The somewhat diverging position of adult males from the general trend is clear in Fig. 5. Adult males only occur in high numbers in connection with the mating period during very restricted periods of the year (Marshall \& Orr 1972, Tande 1982), and they were therefore not included in the regression fit here.

\section{Copepod length/weight relationships}

Interspecific relationships

The mathematical relationship between length and weight of an organism is usually expressed as a power function, due to the general growth principle of organisms and the mathematical relationship between length and volume of a body. We therefore also express the length/weight relationships of the copepods by using this formulation, even though an exponential equation generally turned out to have a higher coefficient of determination.

In order to define a wide-range interspecific relationship between copepod carapace length ( $X$, in $\mathrm{mm}$ ) and dry weight $(Y$, in $\mu \mathrm{g}$ ) we used average values from the same sampling occasion for stage $\mathrm{V}$ copepodites Calanus finmarchicus, together with 5 other species, in a regression equation. The individuals represented a range in dry weight from 28 to $278 \mu \mathrm{g}$, and a carapace

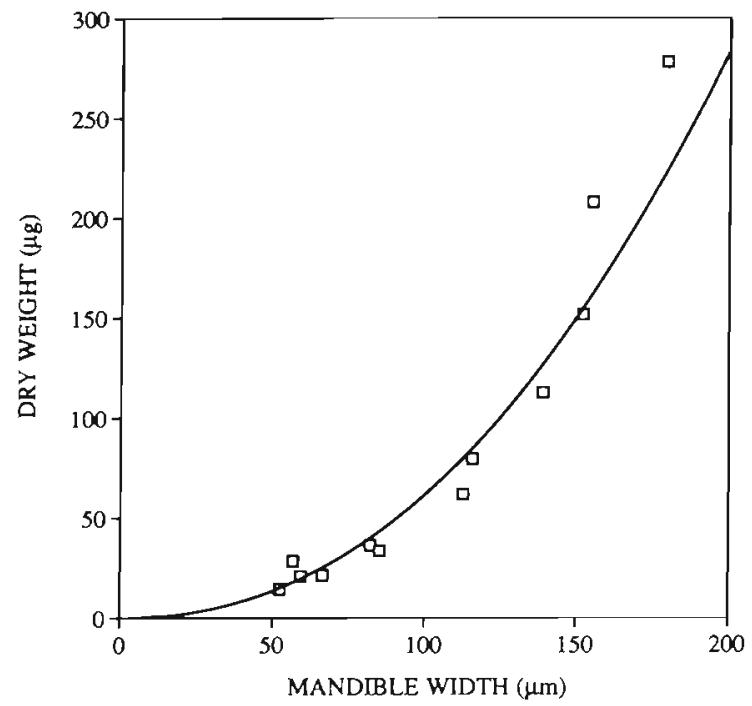

Fig. 6. Relationship between average dry weight ( $\mu$ g) and average mandible width $(\mu \mathrm{m})$ of Calanus finmarchicus (all copepodite stages as separate points) and 5 other copepod species. The graph includes copepodite stage IV of Euchaeta norvegica, and adult females of Metridia lucens, Centropages typicus, Pseudocalanus minutus, and Acartia sp.; points represent the average value of between 9 and 71 measurements length from 0.7 to $2.1 \mathrm{~mm}$. The relationship was best described by the equation:

$$
Y=49.700 X^{2267} \quad r^{2}=0.962
$$

By combining these data with the general relationship between carapace length and mandible width (Eq. 1) a regression equation describing the relationship between the mandible width $(X$, in $\mu \mathrm{m})$ and the individual dry weight ( $Y$, in $\mu$ g) can be defined:

$$
Y=0.00310 X^{2176} \quad r^{2}=0.960
$$

By also including data for the other copepodite stages of Calanus finmarchicus, a regression equation applicable to most copepods is given (Fig. 6):

$$
Y=0.00235 X^{2.208} \quad r^{2}=0.950
$$

Intraspecific relationships for Calanus finmarchicus

The relation between average carapace length $(X$, in $\mathrm{mm}$ ) and average individual dry weight ( $Y$, in $\mu \mathrm{g})$ of Calanus finmarchicus, from August (Fig. 7A), was described by the equation:

$$
Y=37.978 X^{2134} \quad r^{2}=0.983
$$

By using the average mandible width of each developmental stage, the mathematical relationship between individual dry weight ( $Y$, in $\mu \mathrm{g}$ ) and mandible width $(X$, in $\mu \mathrm{m})$ could be calculated (Fig. 7B, excluding adult males):

$$
Y=0.00200 X^{2.215} \quad r^{2}=0.987
$$

Our material on Calanus finmarchicus (Fig. 7A) showed that the average dry weight of stage $V$ copepodites differed by a factor of 1.85 from the beginning of August to the end of September. This partly reflected a parallel change in carapace length, but nevertheless, this result indicates that seasonal variation is important. Unfortunately, we cannot distinguish whether biological or physical factors (different populations sampled) produced this variation in our results.

\section{Individual variability}

Individual variability was evaluated by looking at the intraspecific relationship between carapace length and mandible width of each given species and developmental stage from a single sample (Table 2). The results showed that between 2 and $81 \%$ (average $43 \%, \mathrm{n}=14$ ) of the individual variation in carapace length of a given species/stage could be explained by a corresponding variation in mandible width. This, in turn, means that between 19 and $98 \%$ (average $57 \%$ ) 

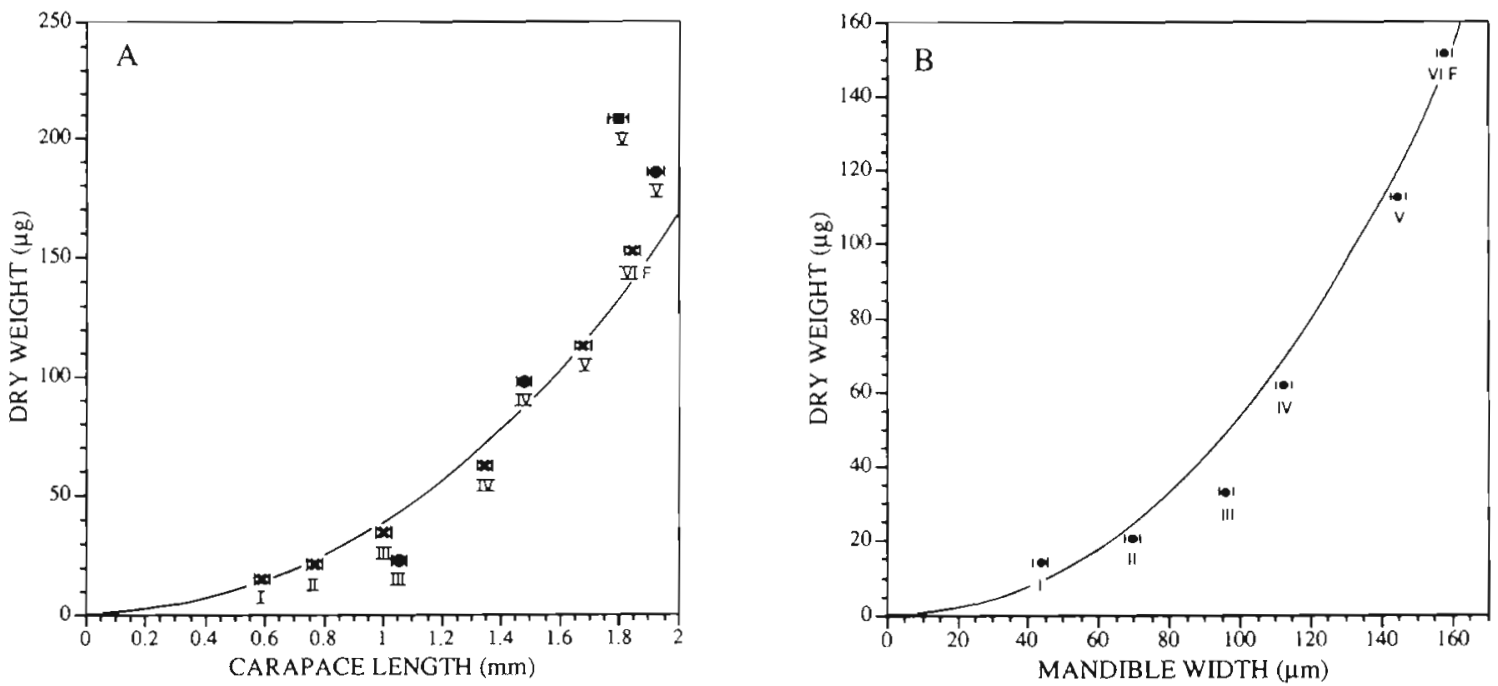

Fig. 7. Calanus finmarchicus. (A) Relationship between average dry weight ( $\mu \mathrm{g}$ ) and average carapace length (mm) of the 6 copepodite stages, excluding adult males. All stages were represented in August ( $\mathbf{x}$ ) whereas May ( $\bullet$ ) and September ( $(\boldsymbol{)})$ only included one or a few developmental stages. Regression line calculated for August data only. Horizontal bars denote $95 \%$ confi-

dence interval. (B) Relationship between average individual dry weight ( $\mu \mathrm{g})$ and average mandible width ( $\mu \mathrm{m})$ in August

of the individual variation in carapace length of animals of a given species and developmental stage was not reflected in a corresponding variation in the mandible width.

\section{DISCUSSION}

\section{Identification}

One of the main problems in using mandible analysis as a technique to estimate predation is certainly the limitations involved in identifying species and developmental stages. In some previous investigations on krill predation, only the width of the mandibles was measured (Stuart \& Pillar 1990, Barange et al. 1991 Gibbons et al. 1991a) and not related to taxonomic group or body weight of the prey. Falkenhaug (1991), studying chaetognath predation in the Barents Sea, identified the copepod prey from mandibles in chaetognath guts, but used only standard values of the body mass of different species. Stuart \& Verheye (1991) estimated prey prosome length from the width of copepod mandibles in the gut contents of chaetognaths, without identification of the species. The method was utilised most completely in 2 previous papers, one on chaetognath predation (Gibbons 1992), and particularly the one on krill predation by Gibbons et al. (1991b), where

Table 2. Relationship between mandible width $(X$, in $\mu \mathrm{m})$ and carapace length ( $Y$, in $\mathrm{mm}$ ), as given by linear regression equations, $Y=a+b X$, of copepods in Raunefjorden, sampled at times given

\begin{tabular}{|c|c|c|c|c|c|}
\hline Species/stage & Month & a & $b$ & $r^{2}$ & $\mathrm{n}$ \\
\hline Calanus finmarchicus adult females & August & 1.139 & 0.005 & 0.492 & 27 \\
\hline Calanus finmarchicus adult males & August & 0.691 & 0.008 & 0.315 & 36 \\
\hline Calanus finmarchicus $\mathrm{C}-\mathrm{V}$ & August & 1.518 & 0.002 & 0.020 & 23 \\
\hline Calanus finmarchicus C-IV & August & 0.551 & 0.007 & 0.719 & 24 \\
\hline Calanus finmarchicus C-III & August & 0.609 & 0.005 & 0.389 & 18 \\
\hline Calanus finmarchicus C-II & August & 0.171 & 0.008 & 0.728 & 17 \\
\hline Calanus finmarchicus C-I & August & 0.445 & 0.003 & 0.187 & 21 \\
\hline Metridia longa adult females & October & 0.580 & 0.008 & 0.411 & 28 \\
\hline Metridia lucens adult females & October & 0.613 & 0.005 & 0.347 & 21 \\
\hline Centropages typicus adult females & October & 0.951 & 0.001 & 0.022 & 17 \\
\hline Temora longicornis adult females & October & 0.073 & 0.005 & 0.754 & 19 \\
\hline Pseudocalanus minutus adult females & October & 0.304 & 0.006 & 0.550 & 15 \\
\hline Acartia sp. adult females & October & 0.244 & 0.008 & 0.808 & 17 \\
\hline Oithona sp. adult females & October & 0.125 & 0.011 & 0.333 & 18 \\
\hline
\end{tabular}


both species/genus identification and prosome length and dry weight were calculated from the recovered mandibles.

We have presented complete data only for Calanus finmarchicus. However, this species is probably the most important prey organism in the Northeast Atlantic, and therefore especially impo85rtant to describe. A proper identification of the juvenile stages of the 7 other species, as well as of more sparsely occurring species, requires further studies. The data for Temora longicornis indicate different regression parameters for this species, so it is therefore especially important to identify mandibles from this species correctly and to use a species-specific regression equation for them.

Although our descriptions of the different mandible shapes seem sufficient for a proper identification, some uncertainties remain. For example, the mandibular teeth are difficult to separate from cusps, especially for Acartia sp. and Oithona sp., when using a light microscope, since the mandible edge is 3-dimensional. Scanning electron microscopy (SEM) would be a preferable technique, and has been used to study the complex mandible edge on 11 species of copepods (Sullivan et al. 1975). However, applying SEM in routine analysis of a large volume of material is impractical. Accordingly, we must accept some doubtful identi-
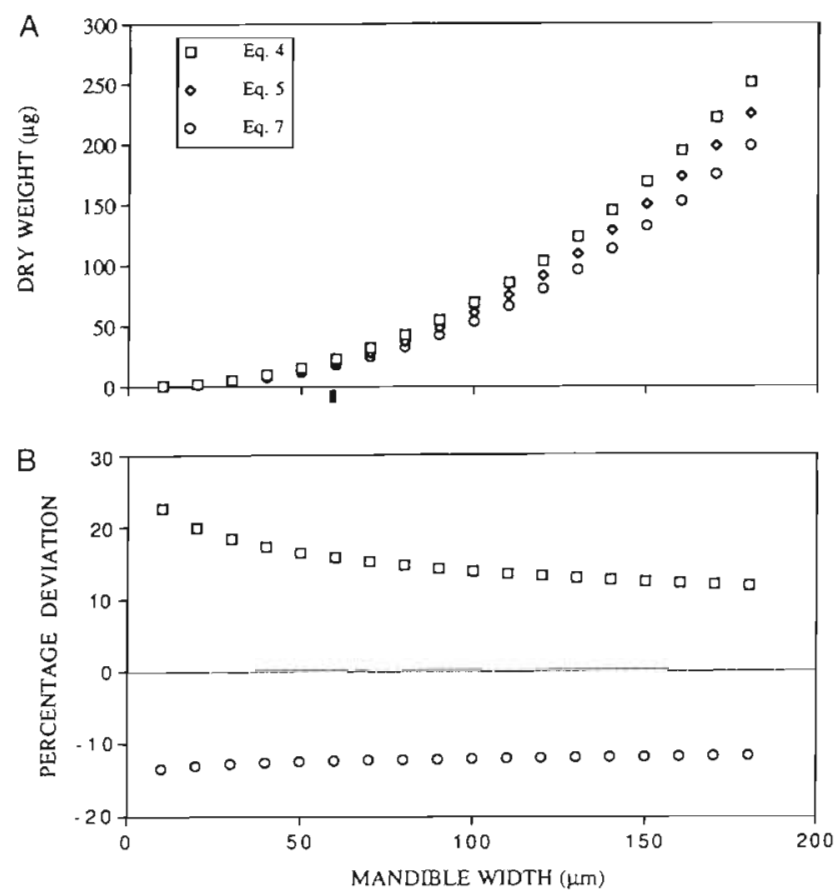

Fig. 8. Sensitivity analysis of predicted dry weights using Eqs. (4), (5) and (7). (A) Dry weight/mandible width relationships given by the 3 equations. (B) Eq. (5) used as a reference showing the relative deviation from the reference for the other 2 equations fications in routine gut-content analyses, but usually this will not be critical.

\section{Prey biomass estimations}

The mandible-analysis technique, fully utilised, can provide a way of estimating the predation rate in terms of prey biomass. This is an important step when applying the method in studies on the energy budgets of predators and the energy flow in food webs. However, such calculated estimates have inherent errors that cause uncertainties in the accuracy and precision, which hitherto have been unknown when using this technique. We have therefore studied this problem with some care.

Any of the presented regression equations relating copepod body mass to mandible width could be used to estimate consumed prey biomass, but will all probably produce a more or less biased estimate. The ideal would be to use species- and season-specific regression equations on each occasion. In addition, a considerable geographical variation in body size (cf. Båmstedt \& Ervik 1984) implies that a set of such equations for each region is needed. This is unrealistic and the gain in precision would probably not pay for the enormous work required. In spite of the shortcomings we recommend using a single equation for all mandibles found. In order to evaluate what effects the choice of equation will have upon the estimate, the regression lines are displayed together in Fig. 8A. If Eq. (5) is used as reference, the other equations give body-mass estimates that diverge from the reference. The relative deviation will be a function of the mandible size, as shown in Fig. 8B, but well below $20 \%$ deviation from the reference for typical sizes of mandibles. If the analysed material is dominated by Calanus finmarchicus, Eq. (7) should be used, but even if the more general equation (Eq. 5) is used for such material, this will only introduce an overestimation of less than 15\% (cf. Eq. 7. Fig. 8B).

\section{Individual variability}

Invertebrate predators like krill, amphipods and chaetognaths commonly have only a few copepod mandibles in their stomachs. If individual variations in mandible width are high and unrelated to body size, the precision of the estimated prey biomass will be outside the suggested $20 \%$. Our data indicate that this may be a main problem, since on average $57 \%$ of the variation in carapace length within a defined species and developmental stage was not related to a corresponding variation in mandible width (Table 2). Since 

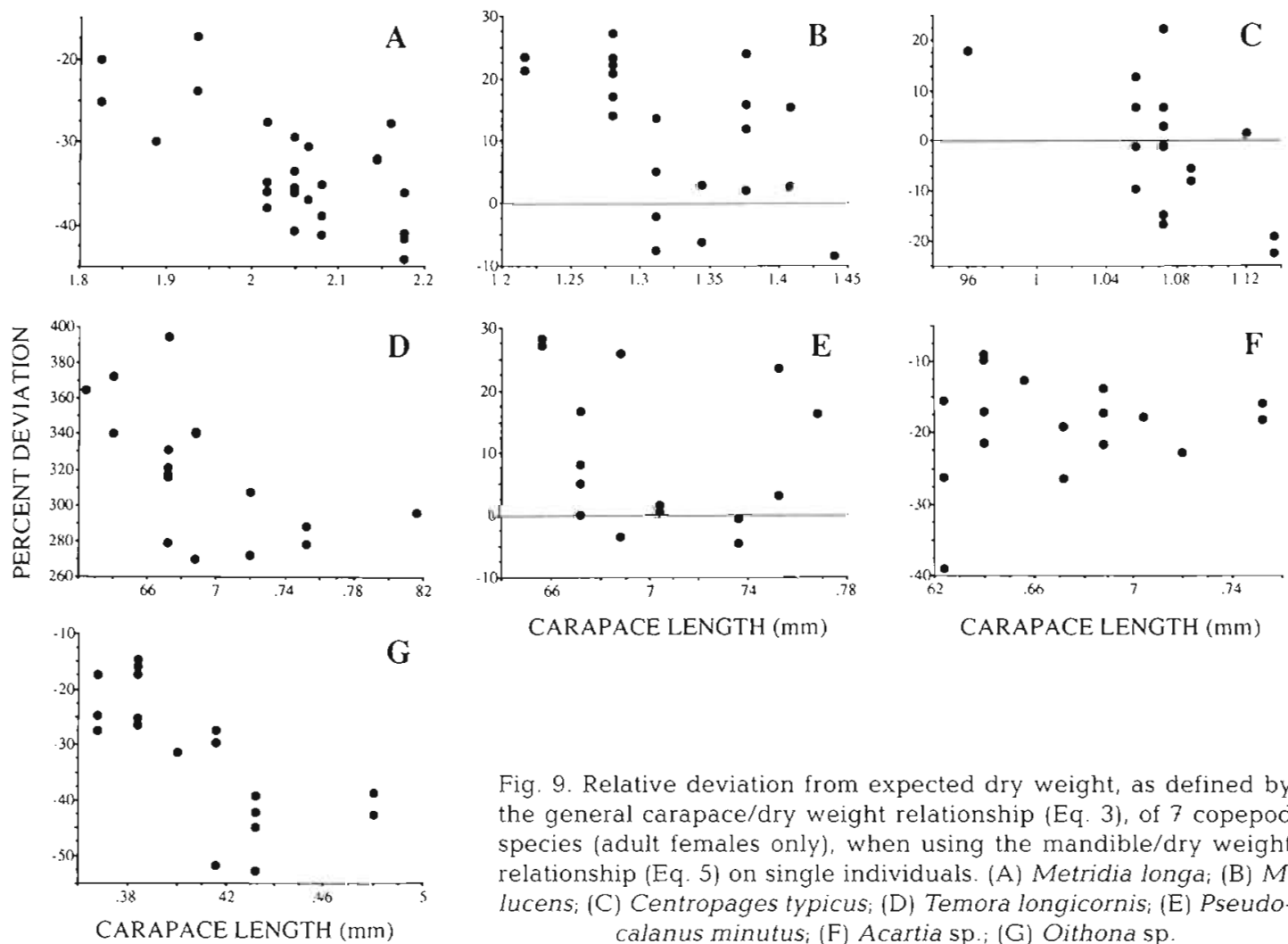

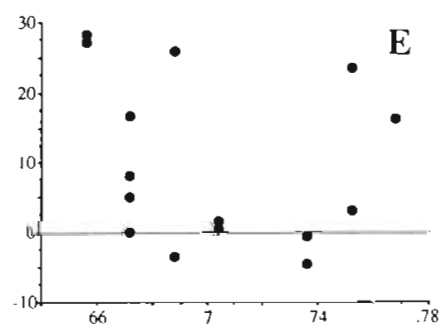

CARAPACE LENGTH $(\mathrm{mm})$

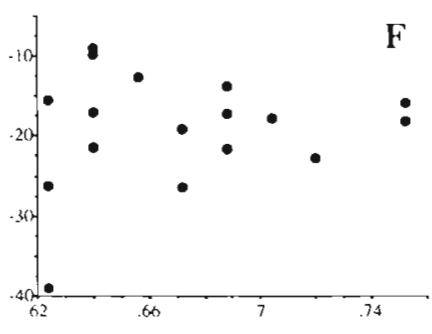

CARAPACE LENGTH $(\mathrm{mm})$

Fig. 9. Relative deviation from expected dry weight, as defined by the general carapace/dry weight relationship (Eq. 3), of 7 copepod species (adult females only), when using the mandible/dry weight relationship (Eq. 5) on single individuals. (A) Metridia longa; (B) $M$. lucens; (C) Centropages typicus; (D) Temora longicornis; (E) Pseudocalanus minutus (F) Acartia sp.; (G) Oithona sp.
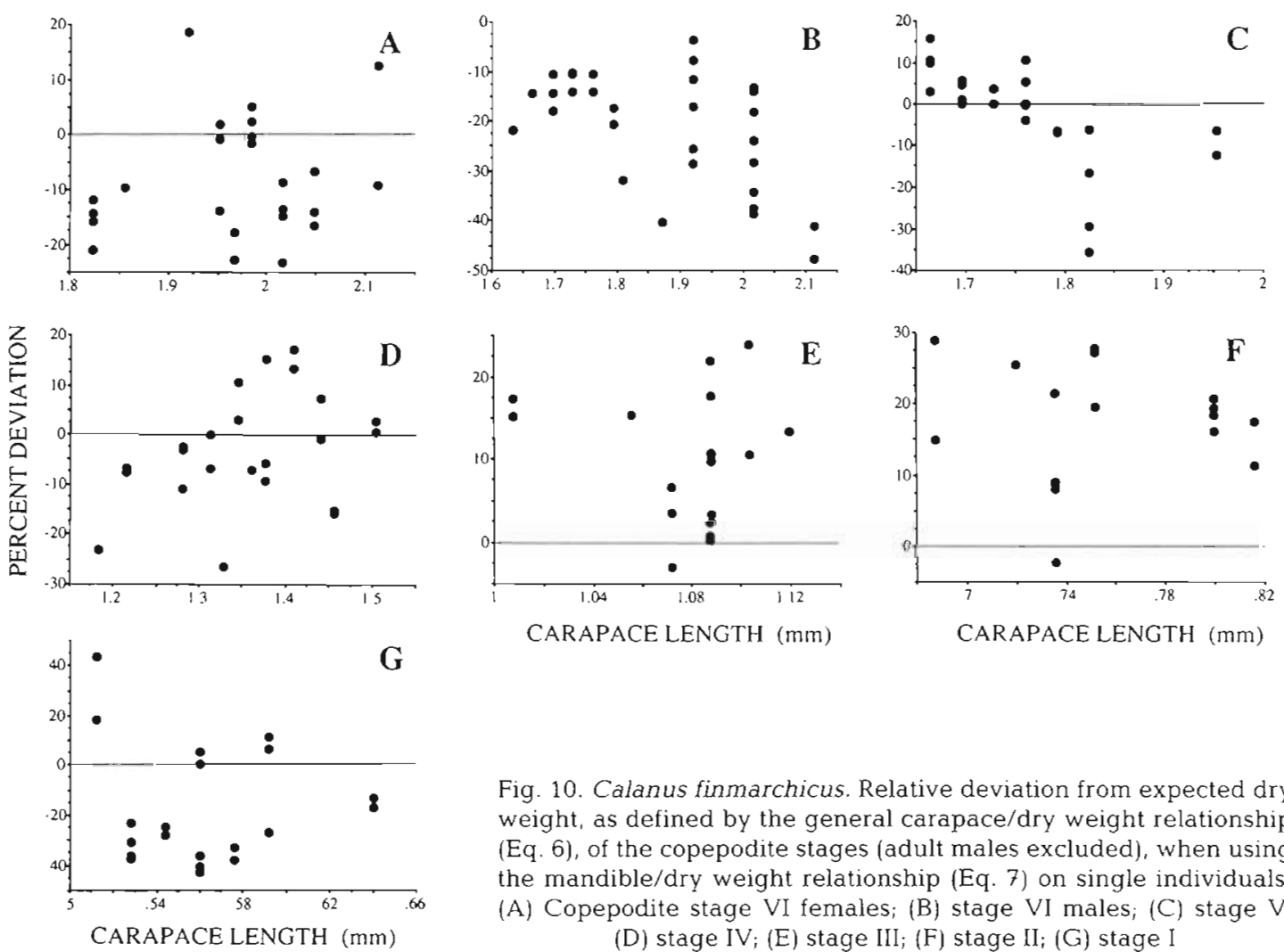

Fig. 10. Calanus finmarchicus. Relative deviation from expected dry weight, as defined by the general carapace/dry weight relationship (Eq. 6), of the copepodite stages (adult males excluded), when using the mandible/dry weight relationship (Eq. 7) on single individuals. (A) Copepodite stage VI females; (B) stage VI males; (C) stage V; (D) stage IV; (E) stage III; (F) stage II; (G) stage I 
we do not have any direct measurements on the dry weight of single individuals, we are unable to compare the predicted dry weights with the actual ones. As an alternative we can compare the results obtained from Eqs. (5) \& (7), based on the mandible measurements, with the results from carapace/weight relationships (Eqs. $3 \& 6$ ), that are commonly used in estimating individual dry weights. The results for the assemblage of copepod species, using Eq. (3) as reference (Fig. 9), indicates an underestimation of the dry weight of Metridia longa, Acartia sp. and Oithona sp., whereas the dry weight of Temora longicornis is heavily overestimated. There is a trend towards decreasing values with size within the species (except for Acartia sp.), indicating that the slope of a regression line within a species/stage is lower than that for the general regres-
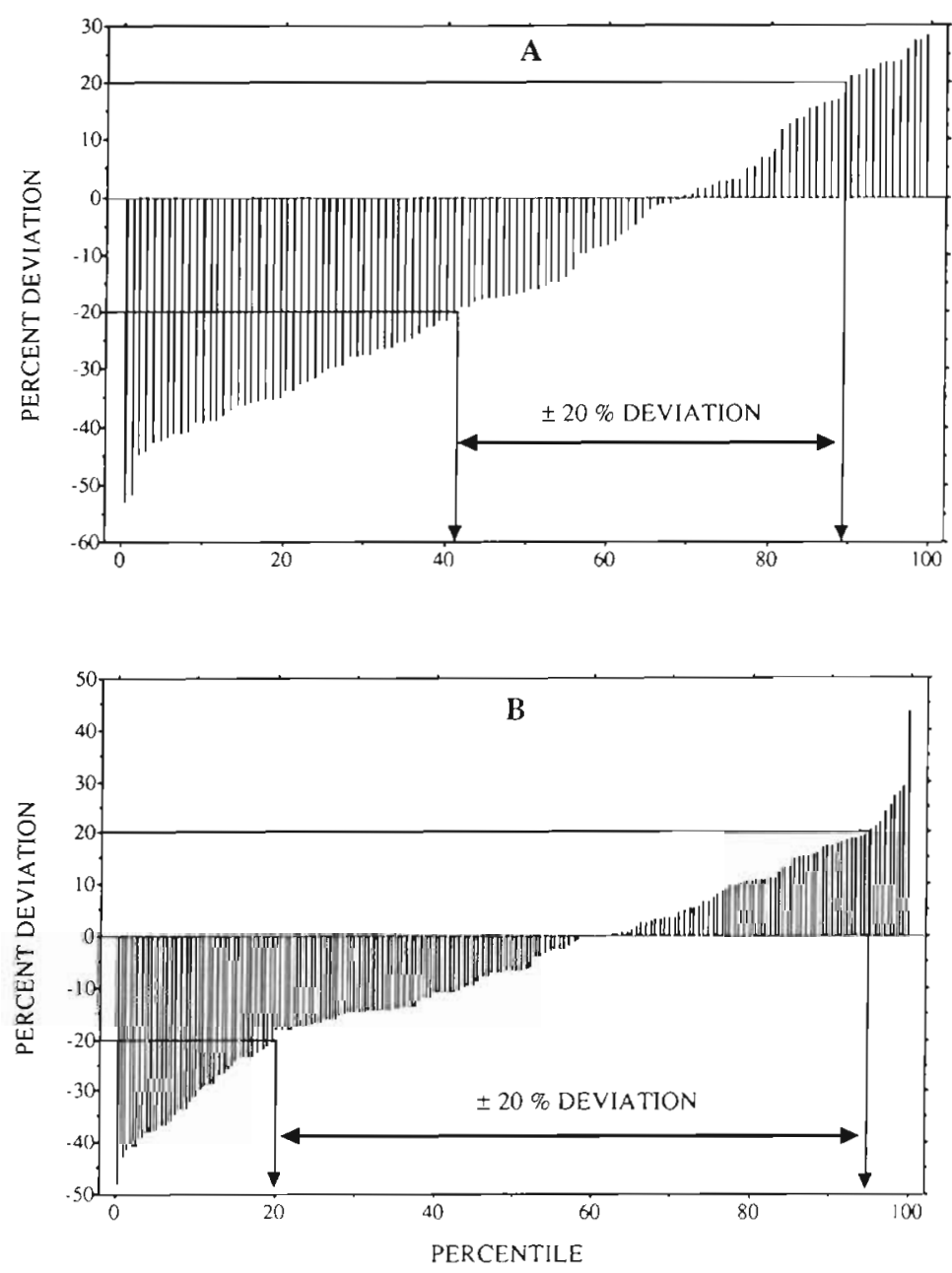

Fig. 11 Relative deviation from the 'reference' individual dry weight in a copepod population, when estimating the dry weight from the mandible width. (A) Adult females of 6 copepod species, calculated by Eq. (5). (B) Calanus finmarchicus (all copepodite stages) calculated by Eq. (7). Reference weight for the copepod assemblage (A) defined by Eq. (3), that of C. finmarchicus (B) by Eq. (6) sion line. The results for Calanus finmarchicus (Fig. 10) show that adult females and males, and copepodite stage I are usually underestimated by Eq. (7), whereas copepodite stage III and II are usually overestimated. For the mixture of species (excluding $T$. longicornis) the estimates vary from $28 \%$ higher to $53 \%$ lower than the reference, with ca $50 \%$ of the individual estimates within $\pm 20 \%$ (Fig. $11 \mathrm{~A}$ ). For C. finmarchicus the predicted value varies from $48 \%$ lower to $44 \%$ higher than the reference, but ca $75 \%$ of the individual estimates were within $\pm 20 \%$ (Fig. 11B).

Due to the individual variability, an estimate of prey biomass based on only one or a few mandibles and using the recommended equation for a mixture of copepods will therefore probably introduce an additional variability of up to ca $50 \%$, but usually considerably less (Fig. 11A). When using the Calanus finmarchicus equation on $C$. finmarchicus material, the individual variability will usually add less than $20 \%$ (Fig. 11B) to the other sources of variability in the prey biomass estimate.

\section{Seasonal variation}

Copepods from high latitudes show a considerable variation in body size, mainly as an adaptation to a seasonally variable food environment (Marshall \& Orr 1972, Durbin \& Durbin 1978, Vidal 1980, Båmstedt \& Ervik 1984, Buchholz \& Prado-Fiedler 1987). Therefore, seasonal corrections may be necessary in order to predict unbiased body weights from length measurements. If the length and weight of a copepod vary as described by the given relationships (Eqs. 3 \& 6) the seasonal variation will not introduce any bias in the estimated body weight, but in situations where the animal builds up a body reserve or where the body reserve is heavily utilised, it is reasonable to suggest that the biomass estimate will be biased. As an example, we have looked at the data from the overwintering population of stage $\mathrm{V}$ copepodites Calanus finmarchicus, from a fjord in northern Norway (Tande 1982) and used our Eq. (6) to estimate the individual body dry weight. The original data shows that the mean dry weight varies by a factor of 3 over the year, whereas the predicted dry weight (from Eq. 6) varies over an annual cycle by a factor 1.5 (Fig. 12). As suspected, the main differences in the seasonal trend are found at the end of the overwintering and starving period (winter) and during summer/autumn, when there is a heavy load- 


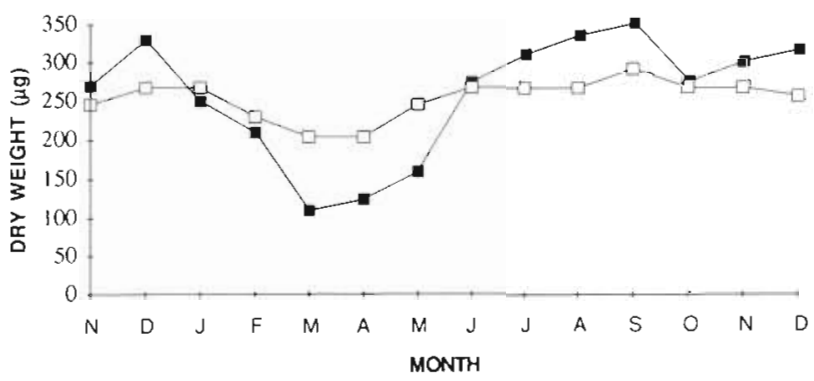

Fig. 12. Calanus finmarchicus, stage $V$ copepodites. Example of a seasonally varying length/weight relationship of a copepod species. (ロ) Original data from Tande (1982). (a) Predicted dry weights calculated by using the original data on carapace length (Tande 1982) and our Eq. (6)

ing of body reserves as a preparation for overwintering. In March the predicted dry weight overestimates the true one by ca $90 \%$, whereas in August, September and December the true weight is underestimated by $20 \%$ (Fig. 12). This source of bias is therefore assumed to be more serious when estimating the dry weight from length/weight relationships of copepod species without any seasonal correction, but the degree of error is certainly species dependent and probably directly related to the seasonal variation in stored energy of the species.

Acknowledgements. We thank Tom Noji, Institute of Marine Research, Bergen, for instruction and valuable help with the Zeus image analysis system; Stein Kaartvedt, Biological Department, University of Oslo for suggesting improvements in the manuscript; and the Nordic Council for Marine Biology, for a scholarship to one of us (K.K.). Three colleagues at our department are especially acknowledged for their help: Elin Holm for making some of the drawings, Tore Høisæter for critical comments, especially on the statistics and Knut $\AA$ rrestad for running the correspondence analysis. We also thank 2 referees for constructive critique.

\section{LITERATURE CITED}

Båmstedt, U., Ervik, A. (1984). Local variations in size and activity among Calanus finmarchicus and Metridia longa (Copepoda, Calanoida) overwintering on the west coast of Norway. J. Plankton Res. 6: 843-857

Barange, M., Gibbons, M. J., Carola, M. (1991). Diet and feeding of Euphausia hanseni and Nematoscelis megalops (Euphausiacea) in the northern Benguela Current: ecological significance of vertical space partitioning. Mar. Ecol. Prog. Ser 73: 173-181

Beklemishev, C. W. (1954). The discovery of silicios formations in the epidermis of lower crustacea. Dokl. Akad. Nauk SSSR 97: 543-545

Beklemishev, C. W. (1959). Anatomy of mouth parts of copepods (masticatory surface of the mandibles in some Calanids and Eucalanids). Trudy Inst. Okeanol., Akad.

This article was presented by J. Mauchline, Oban, UK
Nauk S.S.S.R 30:148-155 (in Russian)

Braak, J. F. C. ter (1986). Canonical correspondence analysis: a new eigenvekten technique for multivariate direct gradient analysis. Ecology 67: 1167-1129

Buchholz, F., Prado-Fiedler, R. (1987). Studies on the seasonal biochemistry of the northern krill Meganyctiphanes norvegica in the Kattegat. Helgoländer Meeresunters. 41. $443-452$

Durbin. E. G., Durbin, A. G. (1978). Length and weight relationships of Acartia clausi from Narragansett Bay, R.I. Limnol. Oceanogr. 23: 958-969

Estep, K W., Maclntyre, F. (1989). Counting, sizing and identification of algae using image analysis. Sarsia 74: 261-268

Falkenhaug, T (1991). Prey composition and feeding rate of Sagitta elegans var. arctica (Chaetognatha) in the Barents Sea in early summer. In: Sakshaug, E., Hopkins, C. C. E., Øritsland, N. A. (eds.) Proceedings of the Pro Mare Symposium on Polar Marine Ecology, Trondheim, 12-16 May 1990. Polar Res. 10(2): 487-506

Gibbons, M. J. (1992). Diel feeding and vertical migration of Sagitta serratodentata Krohn tasmanica Thomson (Chaetognatha) in the southern Benguela. J. Plankton Res. 14: $249-259$

Gibbons, M. J., Barange, M., Pillar, S. C. (1991a). Vertical migration and feeding of Euphausia lucens (Euphausiacea) in the southern Benguela. J. Plankton Res. 13: $473-486$

Gibbons, M. J., Pillar, S. C., Stuart, V. (1991b). Selective carnivory by Euphausia lucens. Cont. Shelf Res. 11: 625-640

Itoh, K. (1970). A consideration on feeding habits of planktonic copepods in relation to the structure of their oral parts. Bull. Plankton Soc Japan 17: 1-10 (in Japanese with English abstract)

Marshall, S. M., Orr, A. P. (1972). The biology of a marine copepod. Springer-Verlag, Berlin

Øresland, V (1987). Feeding of the chaetognaths Sagitta elegans and S. setosa at different seasons in Gullmarsfjorden, Sweden. Mar. Ecol. Prog. Ser. 39: 69-79

Oresland, $V$ (1990). Feeding and predation impact of the chaetognath Eukronia hamata in Gerlache Strait, Antarctic Peninsula. Mar. Ecol. Prog. Ser. 63: 201-209

Ricker, W E. (1973). Linear regression in fishery research. J. Fish. Res. Bd Can, 30: 409-434

Stuart, V., Pillar, S. C. (1990). Diel grazing patterns of all ontogenetic stages of Euphausia lucens and in situ predation rates on copepods in the southern Benguela upwelling region. Mar. Ecol. Prog. Ser. 64: 227-241

Stuart, V., Verheye, H. M. (1991). Diel migration and feeding patterns of the chaetognath, Sagitta friderici, off the west coast of South Africa. J. mar. Res. 49: 493-515

Sullivan, B. K., Miller, C. B., Peterson, W T., Soeldner, A. H. (1975). A scanning electron microscope study of the mandibular morphology of boreal copepods. Mar. Biol. 30 : $175-182$

Tande, K. S. (1982). Ecological investigations on the zooplankton community of Balsfjorden, northern Norway: generation cycles, and variations in body weight and body content of carbon and nitrogen related to overwintering and reproduction in the copepod Calanus finmarchicus (Gunnerus). J. exp. mar. Biol. Ecol. 62: 129-142

Vidal, V. (1980). Physioecology of zooplankton. I. Effects of phytoplankton concentration, temperatur, and body size on the growth rate of Calanus pacificus and Pseudocalanus sp. Mar. Biol. 56: 111-134

Manuscript first received: April 21, 1993

Revised version accepted: February 8, 1994 